Original Research Article

\title{
Computer assisted learning vs. conventional teaching in experimental Pharmacology: perception of second year medical students
}

\author{
Rohit M. Sane*, Pradeep R. Jadhav
}

Department of Pharmacology, MGM Medical College, NaviMumbai, Maharashtra, India

Received: 31 January 2019

Accepted: 05 February 2019

*Correspondence to:

Dr. Rohit M. Sane,

Email: rohitsane7@ hotmail.com

Copyright: (C) the author(s), publisher and licensee Medip Academy. This is an openaccess article distributed under the terms of the Creative Commons Attribution NonCommercial License, which permits unrestricted noncommercial use, distribution, and reproduction in any medium, provided the original work is properly cited.

\begin{abstract}
Background: The main pool of pharmacology practical teaching is formed by the use and demonstration of animal experiments. Animals have been used to demonstrate the effect of various drugs in experimental pharmacology classes, in the lab. The practical sessions in pharmacology training involving animal experiments are still taught by traditional teaching methods. Rapid development of information technology has led to newer trends in teaching and learning using Computer Assisted Learning (CAL). Keeping it in mind we decided to undertake this study to assess the perception of CAL in $2^{\text {nd }}$ year MBBS students over conventional teaching in experimental pharmacology.

Methods: This was an observational, questionnaire-based study. A total of hundred undergraduate MBBS ( $2^{\text {nd }}$ year) students participated. Participants were first demonstrated an animal experiment by conventional teaching method followed by the same animal experiment demonstration on CAL. Students' feedback was recorded on a questionnaire and analyzed.

Results: The mean age of the participants was $19.88 \pm 1.28$ years. The study overall observed that $62 \%$ preferred CAL to conventional (38\%). Majority of the participants' thought CAL $(63 \%)$ helps to understand better over conventional $(28 \%)$ and that CAL $(63 \%)$ is time independent over conventional $(28 \%)$. More than $85 \%$ felt that CAL was more explanatory and provided a better learning experience.

Conclusions: Students preferred CAL to conventional teaching, in experimental pharmacology. It also provided insight on perception and experience of students towards CAL for experimental pharmacology. However, further studies are warranted to assess the knowledge, cognitive and psychomotor skills of students.
\end{abstract}

Keywords: CAL, Conventional teaching, Experimental pharmacology, Perception

\section{INTRODUCTION}

Pharmacology is a complex and self-evolving subject. The undergraduate curriculum in pharmacology must be suitable, clinically oriented and helpful in making decisions in therapeutics. ${ }^{1}$ Undergraduate teaching in pharmacology involves theory and practical sessions and practical teaching has been the core of undergraduate pharmacology learning. The main pool among practical teaching is formed by the use and demonstration of animal experiments. Animals have been used to demonstrate the effect of various drugs in experimental pharmacology classes, in the lab.
Animal use in research studies has raised concerns and legal issues subjecting the use of animals to various ethical and regulatory bodies.

The practical sessions in pharmacology training involving animal experiments were perceived to be unnecessary by medical students, educationists and other policy makers as the learning objectives of these practical sessions primarily focus on observational, analytical and interpretative skills, which are components of the cognitive domain and not psychomotor domain. ${ }^{2,3}$ Thus, rapid development of information technology has led to newer trends in teaching and learning such as CAL (Computer Assisted Learning). ${ }^{4}$ 
Preliminary data indicate that the introduction of multimedia CAL is popular with undergraduates. ${ }^{5}$

With the above thought in mind, authors have decided to undertake this study to assess the perception of CAL in $2^{\text {nd }}$ year MBBS students over conventional teaching in experimental Pharmacology.

\section{METHODS}

This was a pilot study conducted in the Department of Pharmacology. Permission of the Institutional Ethics Committee was taken before commencement of the study. An informed written consent was taken from each participant before being included in the study.

This was an observational, questionnaire-based study and the sample size was 100 participants. Study participants were $2^{\text {nd }}$ year undergraduate medical students. The study was conducted at the Department of Pharmacology, MGM Medical College, Navi Mumbai between January and February 2019.

\section{Inclusion criteria}

- Undergraduate medical students studying in 2nd year

- Either sex

- Age 18 to 23 years.

\section{Exclusion criteria}

- $\quad$ First year, third year and fourth year medical students and medical Interns

- Participants not willing to give informed consent

- Participants with prior exposure to CAL on experimental pharmacology.

Undergraduate medical students studying in the $2^{\text {nd }}$ year were approached to participate in this study. The participants were explained the purpose of the study and consent was obtained. Participants were divided into 5 groups for the ease of conducting the study in small groups. Each group was first demonstrated an animal experiment (evaluation of Analgesic activity on Eddie's hot plate) which is a part of the curriculum by conventional teaching followed by demonstration the same experiment (Analgesic activity on Eddie's hot plate) on CAL (MediMation software).

After the CAL demonstration, participants' feedback was then recorded in the perception questionnaire, adapted from Sharma D et al, having 9 questions with 3 answers options each. ${ }^{6}$

\section{Statistical analysis}

Data was entered-using MS-Excel and analyzed in SPSS software. Descriptive statistics was used to describe the data. The data was expressed in actual number and percentage.

\section{RESULTS}

In the present study, authors observed that the mean age of the participants was $19.88 \pm 1.28$ years. The male to female ratio was 1.86:1. The responses to the feedback questionnaire are summarized in Table 1.

In this study, majority participants' thought CAL (63\%) helps to understand better over conventional (28\%). Participants stated that CAL $(63 \%)$ was time independent over conventional (28\%). More than $85 \%$ felt that CAL was more explanatory and provided a better learning experience than conventional. However, participants perceived conventional $(74 \%)$ to be more interesting than CAL (26\%) and they also felt that conventional (58\%) offered a realistic experience better to CAL (42\%) with majority thinking that $\mathrm{CAL}(53 \%)$ was more time consuming than conventional $(39 \%)$.

In this study, majority of the participants preferred CAL $(62 \%)$ to conventional teaching $(38 \%)$ for experimental pharmacology (Table 1).

Table 1: Responses of the participants to the feedback questionnaire.

\begin{tabular}{|lll|l|}
\hline Questions & Yes $(\%)$ & No $(\%)$ & Can't say $(\%)$ \\
\hline Do you think CAL helps to understand better over conventional? & 63 & 28 & 9 \\
\hline Do you think CAL is more time consuming than conventional? & 53 & 39 & 8 \\
\hline Do you think CAL is time independent over conventional? & 63 & 28 & 9 \\
\hline Do you think CAL is more interesting than conventional? & 26 & 74 & 0 \\
\hline Do you think CAL is explanatory over conventional? & 88 & 12 & 0 \\
\hline $\begin{array}{l}\text { Do you think CAL would be better for practical demonstration than } \\
\text { conventional? }\end{array}$ & 70 & 30 & 0 \\
\hline Do you think CAL offers a better learning experience than conventional? & 86 & 14 & 0 \\
\hline \begin{tabular}{l} 
Do you think CAL offers a realistic experience similar to conventional? \\
\hline $\begin{array}{l}\text { Would you prefer CAL overall over Conventional, for experimental } \\
\text { Pharmacology? }\end{array}$
\end{tabular} & 62 & 58 & 0 \\
\hline
\end{tabular}




\section{DISCUSSION}

CAL (Computer Assisted Learning) is a newer form of innovative teaching-learning modality that offers a better and a complete experience of student-centric learning. In this study, authors explored to understand whether CAL could be an alternative to conventional teaching in experimental pharmacology; and gauged the perception and experience of students towards CAL over conventional teaching, in experimental pharmacology.

In this study, authors observed that majority of the participants' thought CAL (63\%) helps to understand better over conventional (28\%). Participants stated that CAL $(63 \%)$ is time independent over conventional (28\%). More than $85 \%$ felt that CAL was more explanatory and provided a better learning experience than conventional. Majority of the participants $(70 \%)$ preferred CAL for practical demonstration.

On the other hand, participants perceived conventional (74\%) to be more interesting than CAL (26\%) and they also felt that conventional $(58 \%)$ offered a realistic experience better to CAL (42\%) with majority thinking that CAL $(53 \%)$ was more time consuming than conventional (39\%).

Overall in this study, authors observed that participants preferred CAL (62\%) to Conventional (38\%) for experimental pharmacology teaching.

Similarly, in a study conducted by Sharma D et al, it was noted that CAL helps to understand better, is time independent and is also a better explanatory tool, over conventional. ${ }^{6}$ Likewise, they also felt that conventional was more interesting than CAL. However, in their study they found that conventional was more time consuming over CAL; and in current study authors noted that CAL was more time consuming over conventional. Overall, CAL was preferred and was better perceived to conventional in their study as well as present study.

\section{Advantages of computer assisted learning}

CAL is helpful for both students and teachers. Modern computers with multimedia capabilities and presentational benefits can provide an interactive and personalized learning experience and thus promote active and selfdirected learning. ${ }^{7,8}$ It offers an advantage to the students to learn at their convenience and pace; it can save the time as well as resources of the faculty. ${ }^{9}$ CAL increases the understanding of the theoretical concepts when it is applied in the setting of simulated experiments. ${ }^{10}$ The drug effect can easily be seen on CAL rather than on conventional which is time consuming, more expensive with related to keeping and maintain animals and drugs, and is laborious.

\section{Disadvantages of computer assisted learning}

In CAL, there is no handling of any animals and neither any observation of biological variation in responses. This limits hands on practical experience. CAL may be easily forgotten in comparison to traditional animal experiments. ${ }^{2}$ CAL is expensive in the initial stages of implementation in the curriculum. Technical problems with computer occurring during the class are other disadvantages with CAL. Technical snags are commonly encountered during CAL learning sessions, which can be precluded with good technical support. ${ }^{11}$ Development of software may be costly initially and difficult to implement. Training the staff may also take some time.

\section{CONCLUSION}

In conclusion, students preferred CAL to conventional teaching, in experimental pharmacology. The study provided insight on perception and experience of students towards CAL for experimental pharmacology. However, further prospective comparative studies are warranted to assess the knowledge, cognitive and psychomotor skills of students.

\section{Funding: No funding sources}

Conflict of interest: None declared

Ethical approval: The study was approved by the Institutional Ethics Committee

\section{REFERENCES}

1. Vasundara K, Pundarikaksha HP, Vijendra R, Girish K, Jyothi R, Srinivasa P. Existing and expected practical medical pharmacology curriculum - a survey. J Clin Diag Res. 2011;5(2):340-3.

2. Dewhurst D. Is it possible to meet the learning objectives of undergraduate pharmacology classes with non-animal models? InProc. 6th World Congress on Alternatives \& Animal Use in the Life Sciences, Tokyo. AATEX. 2008;14:207-12.

3. Hughes IE. Do computer simulations of laboratory practicals meet learning needs?. Trends Pharmacol Sci. 2001 Feb 1;22(2):71-4.

4. John LJ. A review of computer assisted learning in medical undergraduates. J Pharmacol Pharmacother. 2013;4(2):86-90.

5. Stevens R, Sewell R. The replacement of pharmacology practicals by multimedia computer technology. Pharmaceut J. 1993;251(6758):E11-3.

6. Sharma D, Malhotra P. A comparison of computer assisted learning and practical animal experiment for undergraduate medical students in pharmacology curriculum - a questionnaire based study conducted in a medical college of North India. Int $\mathbf{J}$ Basic Clin Pharmacol. 2016;5(6):2581-4.

7. Moss S. Computer technology in education. Pharm J. 1993;251:491.

8. Baby LT, Kavalakkat JC, Abraham S, Sathianarayanan S. CAL: A modern tool for Pharmacology. Internet J Med Simulation. 2009;2(2).

9. Brain S, Dewhurst DG, Williams AD. Evaluation of the usefulness of a computer-based learning program 
to support student learning in pharmacology. ALT-J. 1999 Jan 1;7(2):37-45.

10. Sewell RD, Stevens RG, Lewis DJ. Pharmacology experimental benefits from the use of computerassisted learning. Am J Pharmaceut Education. 1996 Sep 1;60(3):303-7.

11. Govindaraja C, Prakash HJ, Annamalai C, Vedhavathy SS. Computer assisted learning: Perceptions and knowledge skills of undergraduate medical students in a Malaysian medical school.
National J Physiol Pharma Pharmacol. 2011 Jul $1 ; 1(2): 63-7$.

Cite this article as: Sane RM, Jadhav PR. Computer assisted learning vs. conventional teaching in experimental Pharmacology: perception of second year medical students. Int J Basic Clin Pharmacol 2019;8:438-41. 